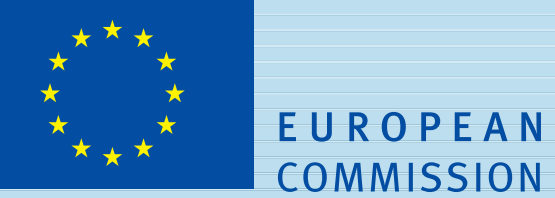

Community research

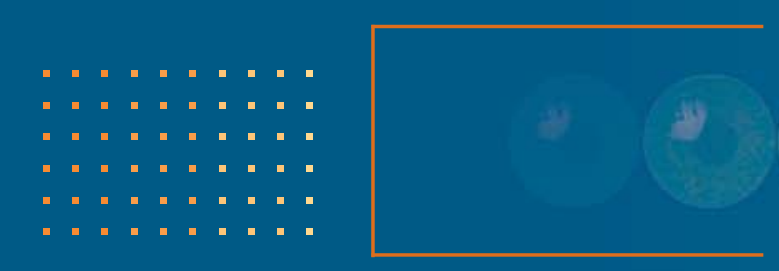

Deliberating Foresight Knowledge for Policy and Foresight Knowledge Assessment

November 2005

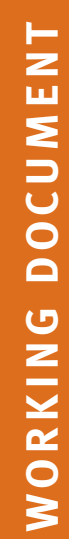




\section{Interested in European research?}

RTD info is our quarterly magazine keeping you in touch with main developments (results, programmes, events, etc.). It is available in English, French and German. A free sample copy or free subscription can be obtained from:

European Commission

Directorate-General for Research

Information and Communication Unit

B-1049 Brussels

Fax (32-2) 29-58220

E-mail: research@cec.eu.int

Internet: http://europa.eu.int/comm/research/rtdinfo/index_en.html

\section{EUROPEAN COMMISSION}

Directorate-General for Research

Directorate K - Social sciences and humanities; foresight

Unit K.2 - Scientific and technological foresight

Contact: René von Schomberg

Office SDME 07/70

B-1049 Brussels

Tel. (32-2) 2990160

E-mail: rené.von-schomberg@cec.eu.int 


\title{
Deliberating Foresight Knowledge for Policy and Foresight Knowledge Assessment
}

\author{
A working document from the European Commission Services
}

November 2005

\footnotetext{
René von Schomberg*, Ângela Guimarães Pereira and Silvio Funtowicz **

* René von Schomberg (email: Rene.von-schomberg@cec.eu.int) is at the European Commission, Directorate General for Research. He was previously in the Science and Technology Foresight Unit and since July 2005 in the Ethics and Science Unit.

** Ângela Guimarães Pereira and Silvio Funtowicz are at the Joint Research Centre, Institute for the Protection and Security of the Citizen in the HAZAS Unit -Knowledge Assessment Methodologies Group.

This working paper is written for the publication series Foresight Working Papers, an activity of the Science and Technology Foresight unit of DG Research. The views expressed here are those of the authors and may not in any circumstances be regarded as stating an official position of the European Commission
} 


\section{Europe Direct is a service to help you find answers to your questions about the European Union}

\section{1}

\section{LEGAL NOTICE}

Neither the European Commission nor any person acting on behalf of the Commission is responsible for the use which might be made of the following information.

The views expressed in this publication are the sole responsibility of the author and do not necessarily reflect the views of the European Commission.

A great deal of additional information on the European Union is available on the Internet. It can be accessed through the Europa server (http://europa.eu.int).

Cataloguing data can be found at the end of this publication.

Luxembourg: Office for Official Publications of the European Communities, 2005

ISBN 92-79-00678-9

(C) European Communities, 2005

Reproduction is authorised provided the source is acknowledged.

Printed in Belgium

PRINTED ON WHITE CHLORINE-FREE PAPER 


\section{Table of contents}

I. Introduction

2. Foresight, Deliberation and its relevance to policy 5

3. The nature of foresight Knowledge 13

4. Assessing deliberations informed by foresight knowledge $\quad 14$

5. Integrating Foresight in a complex policy design $\begin{array}{ll}\text { based on visions for the long-term } & 18\end{array}$

6.Foresight as interfaces between science, society and policy 19

7.Knowledge Assessment \& Pedigree structure to assess quality of "foresight knowledge" 23

References 25

$\begin{array}{ll}\text { Annex } & 27\end{array}$ 


\section{Introduction}

This paper gives an overview of the way foresight knowledge is deliberated in policy. It offers also an approach to assess the quality of foresight knowledge generated during foresight exercises. Although "foresight knowledge" is a special case, the idea of having a procedure, approach or method available for assessing the quality of knowledge is tempting: foresight knowledge consists out of various sources such as different scientific disciplines, normative visions on the future, planning, and scenario's. It also receives input from different sectors of society, such as industry, academia and civil society. How can we then assess the quality of knowledge inputs from such diverse sources and its implication for foresight exercises? This working paper is a first attempt to address this subject matter. We realise that this type of work has not been done before, and we hope therefore, that this first attempt will stimulate others to further explore this issue.

Since this paper addresses "knowledge assessment" on "Foresight knowledge", we will first give an overview of what foresight actually is, before entering into the core issue of this paper by inform the reader on what "knowledge assessment" addresses and where it could intervene in the framework of a Foresight exercise. It may thereby also clarify the relevance of knowledge assessment beyond the context of foresight knowledge itself; yet "foresight" is a particular case for which "knowledge assessment" is required as it will become clear in the course of this paper.

The first part of the paper (sections 2 to 6 ) is devoted to the deliberation process in the policy context and especially identifies the normative dimensions of such a process and its consequences for knowledge generation. The second part of the paper (section 6 and further) will enter into the issue of knowledge assessment of foresight knowledge. In both parts of the paper, foresight knowledge is illustrated on issues of sustainable development.

\section{Foresight, Deliberation and its relevance to policy}

\section{I.What is the importance of Foresight and how does it relate to policy?}

The increased speed of scientific and technological developments occurs often in unpredicted ways. Citizens experience these developments as if they are results of autonomous developments, which are, by large, beyond our control. Who would have predicted the consumer resistance to GMOs in the beginning of 1990s or the current dominance of the internet medium in the 1980s? The interrelationships between science, technology and society are becoming more and more complex, and difficult to predict and yet, adequate policy response and anticipation is required. Therefore, thinking, debating and shaping the future (a rough definition of "foresight") is even more essential today to use and guide successfully scientific and technological developments, and to relate it to an improved quality of life in the long run for the citizen in the context of knowledge society

Foresight signifies a shift away from the use of forecasting methods which were discredited in the early 1980s when it was generally acknowledged that technological developments were not that linear and autonomous in nature as previously perceived and above all the interaction with societal developments were emphasised. Thereby the "object" of application of foresight broadened: away from the focus on technological developments as such to entire innovation systems or, even, society as a whole. The relation of foresight and policy developments are therefore, nowadays, to be placed in broad societal perspective.

Policy developments and current governance models are based on specific bodies of knowledge and processes. Foresight knowledge allows us:

- To explore possible futures and develop a vision on such futures

- To identify impacts on society and implications for policy and particular stakeholders and or sectors of society 
- To guide and support the policy process

- To timely mitigate negative impacts or adapt to new situations and exploit positive outcomes

- To deepen dialogue with society

- To improve governance

This Foresight knowledge is helpful to underpin a series of different policy objectives. The box below gives an overview of examples of such objectives.

Box I. Examples of policy objectives of public policy Foresight studies'

\section{Increase societal and economic well-being}

Economic growth and national competitiveness.

Societal well being, covering social, environmental, cultural and economic factors.

Identification of solutions to problematic areas.

Understanding the interaction between technology and the society.

\section{Define priority areas for technology policy}

Make a survey of national technological development.

Stimulate development in priority areas of technology development and research; thus stimulate the development in these areas.

Better understanding the interaction among technologies and to realise gains resulting from this interaction.

Allocate funding for research and the improvement of industrial competitiveness.

\section{Develop technology and innovation policies}

Improve the co-operation among different stakeholders.

Develop the planning and implementation of technology policy.

Understand the best methods and use of Foresight.

\section{International co-operation outreach}

Strengthen international work on Foresight, learn from the experiences of other countries and promote the know-how from ones own country.

Identify global trends (technology development, the development of the markets and the mega trends).

Benchmark national against international development of technology.

The relevance of knowledge assessment of foresight knowledge becomes clear while realising which questions need to be addressed when a Foresight exercise needs to be properly scoped.Although we have just emphasised the broad societal perspective in which foresight is placed, the question immediately emerges on how to properly limit a foresight exercise to the goals you want to achieve at the one hand, and the relevance of a broad societal perspective, on the other. Scoping deals with questions such as setting the proper timeframe and time horizon of a foresight exercise, which methods needs to be use, who need to be consulted, how to identify and attract the right stakeholders etc. Al these questions relate also the knowledge you eventually will be able to produce because of the constraints under which the exercise was scoped. Below a comprehensive overview is given of the 15 essential scoping elements. 
Box 2.The 15 scoping elements of foresight ${ }^{2}$

I. Rationales - what are the arguments for conducting knowledge society foresight? These will depend upon the organisations (especially the sponsor) and communities involved. Rationales will tend to emphasise how things can be done better with the help of foresight. They may also point to other places or areas where foresight has been successfully deployed as exemplars.

2. Objectives - what will knowledge society foresight set out to achieve and by when? Objectives tend to exist at several levels. For instance, an immediate objective of those managinga foresight exercise is its smooth execution. But there will also be higher -level objectives that relate to the rationales offered for conducting foresightso, again, formal objectives tend to be dictated by the organisations and communities involved. Of course, objectives may shift over time and it is not unusual for different actors to hold different objectives for a foresight exercise.

3. Review existing strategic arrangements - how will knowledge society foresight complement or challenge these? Knowledge society foresight can be carried out as a relatively stand -alone activity, which can be particularly useful if the aim is to challenge a consensual order. However, there is the risk that foresight will be simply ignored and dismissed as irrelevant. For this reason, foresight is often embedded in existing strategic processes where it feeds into players' strategies.

4. Orientation - what will be the focus of knowledge society foresight? Foresight can have any number of orientations, but common ones over the last decade have included science and technology, business dynamics, territorial (e.g. urban and regional) visions, and societal problems. Orientation is closely tied to the rationales and objectives of an exercise and is therefore dependent upon similar factors, i.e. the agendas of organisations and communities involved.

5. Level - at what political/economic/social institutional 'level' is knowledge society foresight to be carried out? Foresight is practised at many levels, including national, supra - and sub-national, city, organisational (e.g. company, NGO, etc.), industrial sector, and issue area, to name but a few. The institutional level at which an exercise is conducted will have a significant bearing on many of the other elements outlined here. In particular, knowledge society foresight's objectives and orientation are limited/enabled by an exercise's position and location.

6. Time horizon - how far out is foresight to peer? The average time horizon for national foresight exercises seems to be around 10 - 15 years, although it may be as long as $30+$ or as short as five years. There is some evidence that the time horizons adopted tend to be related to foresight's objectives and orientation. In other words, time horizon tends to depend upon the uses to which foresight is to be put. Of course, this is not to say that foresight has few consequences for the present. As has been argued earlier, a distinguishing feature of foresight is its emphasis upon action in the present. Moreover, foresight takes account of existing strengths and weaknesses, and of historical trends. In this sense, foresight is as much concerned with the past and the present as it is with the future.

${ }^{2}$ Handbook of Knowledge Society Foresight, European Foundation for the Improvement of Living and Working Conditions, Dublin: 2003 
7. Coverage - what sectors/issues/problems will knowledge society foresight seek to cover? Irrespective of an exercise's orientation, it is usually necessary to select the sectors/issues/problems to be covered by foresight, mostly because of resource constraints and the need to organise exercises of manageable proportions.

8. Participation - what should be the breadth of actor engagement in knowledge society foresight? Who participates in a foresight is a central concern of exercise managers, not least because of a perceived need to produce results that are widely considered to be legitimate, robust, and relevant. The need to implement these results is also an important consideration, given the process benefits associated with foresight. Who participates depends upon other elements of foresight's scope, including objectives, orientation, the themes/sectors covered, and the intended audience. Some exercises are quite limited in their breadth of participation, both in terms of actual numbers and the types of actors engaged. Others have set out to directly involve widely disparate groups, including citizens.

9. Consultation - what should be the depth of actor engagement in knowledge society foresight? This can be thought about along two dimensions: 'frequency' and 'reach'. Considering 'frequency' first, it is often thought that the issue of consultation is associated with only the elicitation of expert/stakeholder views on the future, for example, through Delphi or scenario workshops. However, there are a number of points in a foresight exercise where views might be elicited, for example, during the scoping process, during deliberation on the implications of foresight's results, etc. These can often be the most significant (yet often forgotten) consultation points, since they allow participants to make strategic choices about an exercise which, in theory, should engender greater ownership of the process and its outputs. Who is to be consulted at each round of consultation is covered by the second dimension, 'reach'. This is obviously linked to the earlier discussion on participation, although it is unlikely that reach will be to the same extent for each and every consultation. In this respect, reach can be considered to be either 'widespread' or 'narrow'. Although there are no hard and fast rules for selecting any particular consultation approach, the choice s made have implications for the credibility of the outcome of a foresight exercise, for the time needed for its completion, and for its eventual cost.

10. Duration and cost - how long does a foresight exercise last and how much does it cost? Much depends upon the other elements outlined here. So, for instance, if many areas are to be covered and hundreds, if not thousands, of people actively engaged, an exercise is likely to be expensive and time-consuming. More modest exercises are the norm, taking no mo re than I-2 years to complete and costing approx. $€ 100-250 \mathrm{~K}$. These can be described as 'punctual' exercises, in that they are carried out at a fixed point in time. Such exercises might be repeated at later points in time. There are also exercises that are ongoing and these are described as 'continuous'.

I I. Methods - what methods are to be used at the various stages of an exercise? As this handbook argues, foresight methodology is not confined to consideration of approaches for thinking about the future (see Chapters 4-6). Rather, foresight methodology is far broader, tak- 
ing into account the important tasks of coalition building, scoping, organisation and management, implementation, etc. Different methods can be used to address these tasks, many of which a re outlined throughout this handbook.

12. Organisation and management - how can knowledge society foresight be organised and managed? Again, this is heavily dependent upon the choices made with regard to the other scoping elements outlined here.Yet, all too often, organisational models are 'borrowed' uncritically from elsewhere, with insufficient account taken of these other scoping elements. Partly for this reason, there are some common features of foresight exercises, including the use of steering committees and panels of experts and stakeholders. Managing this process, in terms of personnel and knowledge management, is a creative process, but some lessons can be learnt from other experiences.

13. Dissemination - how are the results of knowledge society foresight to be diffused beyond those immediate actors who took part in the exercise? After all, it is usually impossible to intimately involve everyone in the foresight process who is expected to act on its results. This is a non-trivial task, requiring 'translation' of results into palatable messages for consumption often by a variety of groups. One can imagine that knowledge society foresight results applied to the areas of working conditions a and industrial relations would generate results applicable to business, government, and trade unions. Different messages may need to be conveyed to each of these. Of greater certainty is that the 'medium' through which messages will need to be diffused will vary between these groups (as well as within them). Project managers need to be aware of this early on and design their dissemination strategies accordingly.

I4. Implementation - how are the results of knowledge society foresight to be followedup with action? This tends to be a neglected consideration, with project managers often overly preoccupied with getting the foresight process 'right'. Getting the process 'right' can indeed increase the chances of successful follow-up action, but political awareness of the possibilities for follow-up action should ideally be considered from the outset. In most instances, successful implementation involves follow-up action by actors that may not have been directly involved in an exercise. This is particularly challenging, and it is probably wise to ensure that these actors have some involvement in the process at some stage.

I5. Evaluation - how can the outcomes of knowledge society foresight be assessed? Arrangements should be put in place to obtain some measure of whether the exercise has met its objectives: a process known as summative evaluation. But the novelty of knowledge society foresight, especially as applied to the areas of living conditions, working conditions and industrial relations, means that some formative evaluation may also be useful. The latter is not so concerned with outputs and outcomes as it is with processes. A better understanding of these can be used to improve the conduct of future exercises. 


\subsection{Foresight and deliberation}

Foresight activities should be adapted to processes of deliberative democracy of modern western societies. Before entering into the substance of the relation between foresight activities and specific forms of deliberation, we need to clarify the meaning of "deliberation" in the context of deliberative democracy. Deliberation goes obviously beyond the meaning of simple discussions concerning a particular subject matter, and in its broadest meaning can be understood as "free and public reasoning among equals" (Cohen, 1994).

Deliberation necessarily involves both public and individual dimensions and assumes the constraint of equality of participants to such forms of deliberation, thereby contributing both to individual as to public autonomy of the citizen. Deliberation is concerned with the weighing of pro and contra arguments in relation to particular choices, options and measures of public concern with a view on decision making. However, deliberation does not only relate to concrete decision-making processes within the institutions of our formal democracy (e.g. Parliament etc.), but also take place at a certain distance from those concrete decision making processes within civil society at large, e.g. within our informal democracy.

Focusing on the relationship between deliberation and foresight thus requires scholars and policy makers to pay closer attention to the type of communication involved in particular participatory processes rather than taking them at face value. It also requires consideration of the type of institutional levels in which deliberation takes place.

Particular institutional levels of deliberation can entail general constraints relating to the roles of individuals and the way they communicate with each other, such as particular limits to participation or access to particular forms of deliberation (for example, you obviously need to be a parliamentarian to participate in a parliamentary debate).Yet, deliberation is also subject to other type of normative constraints, which relate directly to the nature of the spheres of our society in which these forms of deliberation take place, e.g. the spheres of politics, policy making, the legal system, science etc. The arguments produced in the context of those spheres, do have special features and/ or represent a professional occupation with particular claims (for example the arguments in science are usually characterised by claims concerning the nature of our reality).

Deliberation can also take place at the interface of different spheres, as we will see for example when we deliberate on the basis of foresight knowledge ${ }^{3}$. In this paper we especially explore deliberation, which take place at the policy making level and at the interface between the sphere of science and the sphere of policy making. The deliberation levels which relate to particular spheres, or a particular interface between such spheres can be characterised by boundaries which are shared by all actors involved and within which the deliberation can lead to particular outcomes that can be fed into other levels of deliberations which are constrained by yet another set of distinct normative boundaries. Most often these boundaries are not simple consensual assumptions, which just happen to be simply shared by the actors involved, but may concern fundamental policy or constitutional principles which are the result of longer learning processes and which have to be shared in order to achieve particular quality standards of policies and decisions. For instance, deliberations on risks and safety under product authorisation procedures within the European Union are guided by the policy objective, which is enshrined in the EU treaty, to aim at a high level of protection of the European citizen. The nature of such types of boundaries are determined by the nature of the sphere in which they take place and the learning processes which have taken place within that particular sphere and which have led to the adoption of those boundaries.

Below we will identify and describe all the normative dimensions (see, for a summarized overview, table I), which involve the invocation, implementation and application of "foresight". The normative dimensions consist of a particular scope of deliberation, constrained by particular normative decision modi, normative considerations and an operational rational typical for a particular level of deliberation. It should be noted that the different levels of deliberation neither represent a hierarchy nor necessarily a chronological sequence, as deliberation levels mutually inform and refer to each other: deliberation at each of the particular levels, can spark new deliberation at any of the other levels. 
What follows is an ideal-type of description of all relevant deliberation levels in relation to foresight. The architectural framework of interrelating deliberation levels ensure public responsiveness and accountability of public actors and thereby contribute to the legitimacy of the decision-making process, whereby at the same time the different deliberation levels can ensure a particular quality of the outcome by positively selecting arguments in the light of the standards which are supposed to be met and also by negatively filtering out those arguments and preferences which fall below the (often demanding) constraints of the deliberation level concerned A positive filtering out of arguments towards a consensus is favoured by deliberative procedures, yet, they neither aim at, nor require consensus, and outcomes can be phrased in various terms such as, clarified decision agenda's or outcomes that allow a possible congruency of action of all actors concerned (Grin et al 2004),

Theorists of deliberative democracy work on the clarification of particular levels of deliberation within particular spheres of society. Neblo (2004) describes levels of public deliberation in terms of 'deliberative breakdown'. Fischer (2003) and Dryzek (1990) describe procedures of discursive politics. Grin et al (2004) define particular deliberations as practices of 'reflexive design'. We will elaborate here the deliberation levels with their particular normative dimensions, which need to be addressed while deliberating foresight knowledge for public policy.

The first level concerns a broad political deliberation, which assumes a political consensus on the need for longterm planning when it engages in foresight exercises. At that broad political level, foresight will be understood to early anticipate and identify threats, challenges and opportunities that lie ahead of us. Foresight exercises are essentially about the identification of such threats/challenges/opportunities. It is thereby important to realise that, for instance, a Technology Foresight exercise identifies technologies or other developments that may have an important impact, rather than assessing those technologies themselves:

"The act of identification is an expression of opinion (italics: by authors of this paper) (which amounts to a form of implicit, covert assessment, the assessment of the relative importance of the technologies identified must necessarily follow their identification" (Loveridge. 2004, p.9).

Those "opinions" are unavoidably normative in nature not relating directly to the assessment of the technology but rather to the assessment of their potential with regards to particular threats/challenges and opportunities which have a clear normative dimension in themselves (whereby also the issue of "perceived" threats versus "actual threats" may play a role).A proper foresight exercise should therefore make these dimensions explicit in order to feed the deliberation process on a sound basis before achieving final conclusions. Foresight exercises, in order to be consensual within the broad political debate, therefore, need to refer to widely shared objectives (for instance those in international treaties and constitutions) such as the objective of sustainable development with its recognised three pillars (social, economic and environmental). It is of course also possible to engage in foresight exercises which are build on more controversial assumptions, yet those exercises will then have the function of stimulating and informing a broader public debate rather than aiming at particular policy conclusions and actions. Foresight exercises can be invoked at this political level of deliberation.

At a second level, one can identify deliberation at the policy level which immediately builds upon outcomes of political deliberation. It will need to map and identify those challenges/ threats and opportunities which are (in)consistent with more particular shared objectives, such as a high level of protection of consumers and the environment, sustainable growth and competitiveness of our economy. At this level a policy framework needs to be decided upon which allow for the implementation of foresight in a broad sense, at least by identifying institutions and actors which will take charge of foresight exercises and the allocation of tasks of different parties.A few countries have institutions in place to which those tasks normally are allocated, such as particular councils or departments of ministries. Such institutions can then plan studies which are part of the foresight exercise and can include activities such as (sustainability) impact studies, cost-benefit analysis, SWOT analysis, scenario studies etc. These studies need to make explicit the considerations while exploring particular scenarios, challenges and threats and see whether they are consistent with current factors, for example, the normative consideration, which is based in EU law, that health and environment protection takes precedence over economic considerations. Policy decisions need also to be made whether foresight exercises are done on a permanent basis or are followed up by monitoring practices ${ }^{4}$ in order to see whether particular policy anticipations need to be adjusted. 
Table I. Deliberation levels involving the progressive invocation, application and implementation of foresight with its normative dimensions

\begin{tabular}{|c|c|c|c|}
\hline $\begin{array}{c}\text { Normative deliberation } \\
\text { level/scope of } \\
\text { deliberation }\end{array}$ & $\begin{array}{l}\text { Type of operational } \\
\text { normative rationale }\end{array}$ & $\begin{array}{l}\text { Factors/normative } \\
\text { considerations to be } \\
\text { taken into account }\end{array}$ & $\begin{array}{c}\text { Normative } \\
\text { decision modi }\end{array}$ \\
\hline $\begin{array}{l}\text { Political level/broad } \\
\text { political debate }\end{array}$ & $\begin{array}{l}\text { Political consensus on } \\
\text { long term planning }\end{array}$ & $\begin{array}{l}\text { Invocation of Foresight } \\
\text { Threats/challenges/ } \\
\text { opportunities; normative } \\
\text { reference points:Three } \\
\text { pillars of Sustainable deve- } \\
\text { lopment/Lisbon/Barcelona }\end{array}$ & $\begin{array}{l}\text { Early anticipation/ } \\
\text { identification }\end{array}$ \\
\hline $\begin{array}{l}\text { Political level/Choice of } \\
\text { SD targets and challenges }\end{array}$ & $\begin{array}{l}\text { Aim at high level of } \\
\text { protection Aim at } \\
\text { sustainable growth } \\
\text { Improve quality of life }\end{array}$ & $\begin{array}{l}\text { High Level of protection } \\
\text { Sustainable growth, } \\
\text { competitiveness }\end{array}$ & $\begin{array}{l}\text { Defining/mapping } \\
\text { Threats and Challenges }\end{array}$ \\
\hline $\begin{array}{l}\text { Policy } \\
\text { level/Political/societal }\end{array}$ & $\begin{array}{l}\text { Choice of policy } \\
\text { framework }\end{array}$ & $\begin{array}{l}\text { Implementation of } \\
\text { foresight }\end{array}$ & $\begin{array}{l}\text { Allocation of tasks to } \\
\text { Foresightinstitutions/ } \\
\text { involvement of parties }\end{array}$ \\
\hline $\begin{array}{l}\text { Policy level/Broad policy } \\
\text { debate }\end{array}$ & $\begin{array}{l}\text { cost/benefit analysis } \\
\text { impact analysis }\end{array}$ & $\begin{array}{l}\text { Health/environment takes } \\
\text { precedence over } \\
\text { economic considerations }\end{array}$ & $\begin{array}{l}\text { priority setting/selection } \\
\text { e.g. minimalising costs, } \\
\text { maximilising benefits, } \\
\text { priority to health etc }\end{array}$ \\
\hline $\begin{array}{l}\text { Policy level/Type of } \\
\text { measures }\end{array}$ & $\begin{array}{l}\text { Enabling } \\
\text { Monitoring } \\
\text { practice/ongoing foresight }\end{array}$ & $\begin{array}{l}\text { Proportionality } \\
\text { requirement }\end{array}$ & $\begin{array}{l}\text { measures to enable } \\
\text { Monitoring practice, } \\
\text { Learning practice } \\
\text { development of } \\
\text { indicators/benchmarking }\end{array}$ \\
\hline $\begin{array}{l}\text { Science/policy interface: } \\
\text { scientific and normative } \\
\text { deliberation }\end{array}$ & $\begin{array}{l}\text { Identification of state } \\
\text { of affairs in science/ } \\
\text { normative qualification } \\
\text { of knowledge } \\
\text { Identification of } \\
\text { knowledge gaps }\end{array}$ & $\begin{array}{l}\text { Particular } \\
\text { threats/challenges/ } \\
\text { opportunities } \\
\text { Application of foresight }\end{array}$ & $\begin{array}{l}\text { Normative qualification } \\
\text { of available information. } \\
\text { Relating the quality of } \\
\text { available information to } \\
\text { Importance of challenges } \\
\text { etc }\end{array}$ \\
\hline $\begin{array}{l}\text { science/policy } \\
\text { interface)/Normative } \\
\text { approach to dealing with } \\
\text { acceptability } \\
\text { threats/challenges/opport } \\
\text { unities }\end{array}$ & $\begin{array}{l}\text { Identification of } \\
\text { transformable standards, } \\
3 \text { percent target, etc } \\
\text { scientific and technological } \\
\text { options }\end{array}$ & $\begin{array}{l}\text { (Undefined) normative } \\
\text { standards for acceptability, } \\
\text { safety etc of } \\
\text { threats/opportunities }\end{array}$ & $\begin{array}{l}\text { Choice of transformable } \\
\text { standards: growth rates, } \\
\text { sustainability targets, for } \\
\text { example: reduction of } \\
\text { biodiversity, acceptable } \\
\text { levels of temperature rise } \\
\text {, levels of use of } \\
\text { renewables etc. }\end{array}$ \\
\hline
\end{tabular}


In the framework of this paper, a third deliberation level, e.g. the science/policy interface, is of particular interest since it qualifies the input of a diverse range of knowledge inputs, e.g. those of the science community, stakeholders and possibly the public at large by applying foresight (scenario workshops, foresight techniques/studies/panels etc) to particular issues of concern. The second part of this paper will enter into the quality assessment of the knowledge flows at this deliberation level, but here we will first elaborate on the nature and boundaries of this knowledge flow as such.At the science/policy interface, the state of affairs in science needs to be identified in relation to the identified threats/challenges and opportunities relevant to the subject matter. A particular task lies in the qualification of the available information which already involves a preliminary form of Knowledge assessment by formulating statements whether the available information is sufficient and adequate. The identification of knowledge gaps is a particular task to sort out the state of affairs in science, possibly leading to later recommendations for further scientific studies to close those gaps, or, whether depending on the timelines during which those decisions should be made, particular decision procedures for deciding under conditions of uncertainty need to be taken into account. When communicating the results of the science/policy interface to the policy and political level, the proper handling of uncertainty has to be taken care of (Van der Sluijs et al, 2003), and failure to do so have often lead to disqualifications of the used scientific knowledge base at the political level and in public debate. In the light of uncertain knowledge, particular assumptions must be made whether particular consequences pose in fact a threat to us or not. For example: do we see I, 2 or three degrees temperature rise as unacceptable consequence in terms of climate change? Do we think a 3 percent increase on public and private investments in science and technology by 2010 would make our economy sufficiently competitive? These normative settings of an assumed acceptable particular degree of temperature rise or increase of public/private investment represent "transformable" standards. They change namely in the light of accumulation of new knowledge on the subject matter and therefore need to be rethought on a continuous basis, thereby making Foresight and monitoring practices necessary partners.

\section{The nature of foresight Knowledge}

In order to appreciate any type of knowledge assessment, one needs to take into account the particular features of "Foresight" knowledge. When we discuss foresight knowledge, we tend to use particular argumentation forms. Predominant argumentation forms include analogies thereby making future possible threats and opportunities plausible by analogy of known threats. Counterfactual arguments are also often deployed when we address "What if" questions. The threats and opportunities of biotech have often been explored on the basis of the experience with nuclear technology. Nanotechnology is increasingly being compared on the basis of experience with biotechnology (see for example Grove White et al, 2004). Analogies or counterfactuals, do not allow for predictions but produce prospective plausibility claims, which, however, do have sufficient power to allow us to explore the future on the basis of consolidated knowledge from known areas. Conflicting plausibility claims, make us aware of, and articulate uncertain knowledge whereby these equally plausible claims are based on alternative sources of knowledge (most often from different scientific disciplines). However, these plausibility claims mutually lack any falsificationary power and merely illustrate the argument (see Von Schomberg 2003). These plausibility claims either loose substance or become more persuasive, once empirical research seem to support particular paradigms based on those plausibility claims. For instance, the argument (an analogy) of a "greenhouse effect" stated the plausibility of the occurrence of global warming; an analogy which has been strengthened by actual observed temperature rises over the last decade, although this empirical basis in itself will not be sufficient to proof the thesis of the greenhouse effect(as for those temperature rises exist alternative explanations). Foresight knowledge distinguishes itself from "normal" scientific knowledge (in Kuhn's sense) and shares many aspects (although not identical) with what Ravetz/Funtowicz (1990) have called post-normal science: 
In distinction to normal science, foresight knowledge

I. is non-verifiable in nature since it does not give a representation of an empirical reality. It can, therefore, also not be related to the normal use "predictability" of events. The quality of foresight knowledge is discussed in terms of its plausibility rather than in terms how accurate it is in terms of the predictability of certain events. Foresight exercises are therefore often characterized as "explorative" in nature and not meant to produce predictions.

2. has a high degree of uncertainty und complexity whereby uncertainties exists concerning particular causal relationships and their relevance for the issue of concern.

3. thematises usually a coherent vision whereby relevant knowledge includes an anticipation of "the unknown".

4. has an action-oriented perspective (identification of 'threats/challenges/opportunities and the relevance of knowledge for a particular issue) whereby normal scientific knowledge lacks such an orientation. Foresight exercise mobilise orientation knowledge, making it possible to a diagnosis of the situation. (See Grunwald (2004) andWeber andWhitelegg (2003), for further elaboration of the concept of "orientation knowledge").

5. shares a typical hermeneutic dimension of the social sciences and the humanities, whereby the available knowledge is subject to continuous interpretation (e.g. visions on "the future" or what can account for a "future" is a typical example of such an hermeneutic dimension

6. is more than future-oriented research: it combines normative (transformable, see above for notion of "transformable") targets with socio-economic feasibility and scientific plausibility

7. is per definition multi-disciplinary in nature and, even, very often combines the insights of the social and natural sciences

Foresight knowledge can be understood as a form of "strategic knowledge" necessary for agenda setting, opinion formation and vision development and problem-solving. In the case of underpinning the objective of sustainable development, Grunwald (2004) has captured the characteristics of "strategic knowledge for sustainable development", in which many of the above mentioned general aspects of foresight knowledge reappear, in the following three statements:

- strategic knowledge, as a scientific contribution to sustainable development, consists of targeted and context-sensitive combinations of explanatory knowledge about phenomena observed, of orientation knowledge evaluative judgements, and of action-guiding knowledge with regard to strategic decisions (compare the aspects 4,5 and 7 above)

- this strategic knowledge is necessarily provisional and incomplete in its descriptive aspects, as well as dependent on changing societal normative concepts in its evaluative aspects (compare aspects 2 and 6 above)

- dealing with strategic knowledge of this sort in societal fields of application leads to a great need for reflection on the premises and uncertainties of knowledge itself. Reflexivity and the learning processes building upon it become decisive features in providing strategic knowledge for sustainable development.(relates to aspects I and 3 above)

\section{Assessing deliberations informed by foresight knowledge}

The identification of the different knowledge forms and types of arguments deployed while deliberating foresight knowledge, is a first step to allow an assessment of the quality of such deliberations, arguments and the knowledge itself. In this paper, we limit ourselves to the nature of foresight knowledge within particular deliberations (a complementary argumentation analysis would go much beyond the scope of this paper). The most important preliminary assessment of deliberations will be made possible by an explicit use and the identification of all normative dimensions involved. To our knowledge only a few authors have attempted to go into the issue of knowledge assessment of those deliberations and the knowledge involved. Here we have to clarify what the notion of quality actually means. Traditionally, the assessment of knowledge and arguments has been made on the basis of the analysis of the substance of the arguments, e.g. by involving an evaluation of the truth of assumptions and the soundness of the argument employed. In the case of evaluating the deliberations on the basis of foresight knowledge this would be of little use, other than that one would soon arrive to the conclusion that those arguments will not survive the test of logic and empirical verification. Yet, nobody would contest the "reasonability" of these 
particular deliberations. The more proper approach is, therefore, to relate the substance of the arguments to the deliberations process and to the type of policy discourse which is employed. In parallel to the distinction between normal science and foresight knowledge, one can identify two distinct policy discourses, e.g. the policy defining discourse of agenda setting in which problems are identified and defined and the policy evaluating discourse, in which policy options are evaluated, on the basis of their effectiveness which regard to problem solving. Foresight exercises naturally relate to the problem-defining/exploring policy discourse."Problem-solving" on the basis of normal, explanatory knowledge is not even immediately required (see table 2). Foresight knowledge is part and parcel of a problem-defining and exploring discourse allowing to outline possible policy frameworks as responses to plausible threats/opportunities and challenges.

Table 2: Argumentation forms while deploying foresight knowledge or normal science in relation to the policy discourse

\begin{tabular}{|c|c|c|c|}
\hline $\begin{array}{c}\text { SCIENTIFIC } \\
\text { KNOWLEDGE BASE }\end{array}$ & $\begin{array}{c}\text { Argumentation } \\
\text { Forms based on } \\
\text { knowledge input }\end{array}$ & $\begin{array}{c}\text { Argumentation/ } \\
\text { Problem focus }\end{array}$ & Policy Discourse \\
$\begin{array}{c}\text { FORESIGHT } \\
\text { KNOWLEDGE }\end{array}$ & $\begin{array}{c}\text { PLAUSIBILITY CLAIMS } \\
\text { (such as arguments by } \\
\text { analogy and counterfactuals) }\end{array}$ & DEFINING/EXPLORING & POLICY DEFINING \\
\hline $\begin{array}{c}\text { NORMAL } \\
\text { SCIENCE }\end{array}$ & $\begin{array}{c}\text { PREDICTABILITY } \\
\text { CLAIMS }\end{array}$ & PROBLEM SOLVING & POLICY EVALUATING \\
\hline
\end{tabular}

This particular policy defining discourse is characterised:

- by agenda setting/ and identification of agenda setters in society (which is often also part of the objectives of a foresight activity itself).

- as a learning process with an action orientation but without complete problem definitions: problemdefinitions can equally shift in time as knowledge accumulates or new perspectives enter the debate.

- by discussion on framing of the policy problem in potential policy frameworks.

- by mapping (competing) problem-definitions and its potential for societal consensus or persistent dissent.

- by integrating different (sometimes perceived as incompatible!) demands. For instance in relation to the objective of sustainable development: the representation and interaction of three pillars (environmental, social, economic).

- by assessing knowledge policies and the use of particular knowledge types (and increasingly the acquisition of new knowledge (e.g. initiatives for science policy). The strategic use of knowledge can namely prevent acceptable outcomes, for instance, when knowledge becomes

a. a limitation factor: by overestimating the economic knowledge concerning the costs of big infrastructural projects in relation to the environmental knowledge concerning the sound implementation of big infrastructural projects (paradoxically the planning of a knowledge flow with an initial strong focus on costs and benefits of such projects and a subsequent implementation of those projects in the light of environmental and spatial concerns, systematically drive up the prices of those projects up to point of their cost-ineffectiveness ${ }^{5}$. 
b. a potential legitimizing factor thereby hindering the acceptance of decisions by certain actors: for example in cases where even the acquisition of knowledge can be perceived as a threat: the acquisition of knowledge concerning the ultimate storage of radioactive waste is often perceived by environmental pressure groups as an unjustified early attempt to opt for a particular energy policy option. In the Netherlands this had led in the 1980 s to the situation that the government only did "desk research" on the feasibility of the ultimate storage of radioactive waste under salt-layers in the north of the country and could not investigate the matter by actual explorations of the structure of the salt-layers so that accumulation of knowledge on this matter never became available.

These characteristics of the policy defining discourse on the basis of foresight knowledge contain already the guidelines for the potential assessment of this discourse. In't Veld (200I) has produced design requirements for the use of foresight knowledge (which he calls TO3, consisting out of "future orientation", "design" and "research") in the policy discourse for the particular objective of a strategic integrated environmental and spatial policy (table 3). This policy allows to deliberate on 6 objectives (see table).

In't Veld clearly takes also the approaching of linking the evaluation of knowledge requirements to the process of producing the knowledge by particular actors: knowledge useful for agenda-setting and formulation of visions go side in side with knowledge relevant for coalition-building of stakeholders and assumptions of involved organisations.

As only few authors have addressed the issue of "knowledge assessment" of those deliberations, the earlier paragraphs can be seen as a first overview on which more work needs to be done. One could follow the suggestion which emerges from the work of In'tVeld, that with regard to foresight, a complete "design" of the knowledge and process requirements in relation to policy objectives, needs to be developed in order to assess the quality of a particular project and make it possible that potential knowledge limitation and legitimation factors are identified and circumvented at the early stage.

A service-contract study for the European Commission, managed by the Science and Technology Foresight Unit is underway to propose more concrete guidelines for conducting foresight in the science/policy interface. ${ }^{6}$ 
Table 3. Knowledge and process requirements of six policy objectives of a strategic integrated environmental and spatial policy (after In't Veld (200I))

\begin{tabular}{|c|c|c|c|c|c|c|}
\hline $\begin{array}{c}\text { Deliberation } \\
\text { outcomes }\end{array}$ & $\begin{array}{c}\text { Agenda- } \\
\text { setting and } \\
\text { generating } \\
\text { policy } \\
\text { options }\end{array}$ & $\begin{array}{c}\text { Formulation } \\
\text { of a vision }\end{array}$ & $\begin{array}{l}\text { Coalition- } \\
\text { forming }\end{array}$ & $\begin{array}{c}\text { Mapping } \\
\text { policy } \\
\text { effects in } \\
\text { advance }\end{array}$ & $\begin{array}{c}\text { Increasing } \\
\text { the learning } \\
\text { and } \\
\text { adaptive } \\
\text { potential }\end{array}$ & $\begin{array}{c}\text { Changing } \\
\text { the role } \\
\text { assumptions } \\
\text { of the } \\
\text { organization }\end{array}$ \\
\hline $\begin{array}{l}\text { Knowledge } \\
\text { requirements }\end{array}$ & $\begin{array}{l}\text { link types of } \\
\text { knowledge in } \\
\text { future visions; } \\
\text { i.e. creative } \\
\text { and intuitive } \\
\text { ideas (un) } \\
\text { certain } \\
\text { developments } \\
\text { and } \\
\text { perspectives } \\
\text { from other } \\
\text { policy worlds. }\end{array}$ & $\begin{array}{l}\text { insights of } \\
\text { experts linked } \\
\text { with ideals and } \\
\text { visions in } \\
\text { cohesive and } \\
\text { plausible future } \\
\text { visions.. }\end{array}$ & $\begin{array}{l}\text { knowledge } \\
\text { about the } \\
\text { political } \\
\text { context to } \\
\text { determine } \\
\text { where } \\
\text { coalitions are } \\
\text { possible. }\end{array}$ & $\begin{array}{l}\text { knowledge } \\
\text { about policy } \\
\text { intentions, } \\
\text { about possible } \\
\text { (un)certain } \\
\text { developments. }\end{array}$ & $\begin{array}{l}\text { images are } \\
\text { extremely } \\
\text { surprising, } \\
\text { but relevant. }\end{array}$ & $\begin{array}{l}\text { contribution } \\
\text { and creation } \\
\text { of anomalies } \\
\text { and differing } \\
\text { opinions and } \\
\text { ideas about } \\
\text { role } \\
\text { assumptions. }\end{array}$ \\
\hline $\begin{array}{l}\text { Process } \\
\text { requirements }\end{array}$ & $\begin{array}{l}\text { contribution } \\
\text { from external } \\
\text { players. } \\
\text { Actively seek } \\
\text { variety. }\end{array}$ & $\begin{array}{l}\text { participation by } \\
\text { creative and } \\
\text { intuitive players } \\
\text { and also by } \\
\text { other policy } \\
\text { players who } \\
\text { have wishes } \\
\text { and interests } \\
\text { which may } \\
\text { influence } \\
\text { developments }\end{array}$ & $\begin{array}{l}\text { contribution } \\
\text { from relevant } \\
\text { policy players. } \\
\text { It must be } \\
\text { attractive to } \\
\text { take part } \\
\text { (sometimes the } \\
\text { process needs } \\
\text { to be volun- } \\
\text { tary, sometimes } \\
\text { commitment is } \\
\text { required. }\end{array}$ & $\begin{array}{l}\text { participation } \\
\text { by experts, } \\
\text { politicians, } \\
\text { policy- } \\
\text { makers. }\end{array}$ & $\begin{array}{l}\text { participation } \\
\text { by an } \\
\text { organization } \\
\text { which learns } \\
\text { to take } \\
\text { responsibility. } \\
\text { Breaking } \\
\text { down } \\
\text { institutional } \\
\text { practices } \\
\text { during the } \\
\text { process. }\end{array}$ & $\begin{array}{l}\text { involvement } \\
\text { of external } \\
\text { policy } \\
\text { players, but } \\
\text { also many } \\
\text { internal } \\
\text { players in } \\
\text { what is for } \\
\text { the } \\
\text { organization } \\
\text { an } \\
\text { experimental } \\
\text { phase. }\end{array}$ \\
\hline
\end{tabular}




\section{Integrating Foresight in a complex policy design}

\section{based on visions for the long-term}

In this section, we will give one example of an advanced form of embedded foresight, which can be seen as a result of deliberating foresight at the above elaborated various levels and leading to a full implementation of foresight in a long-term policy context. Such type of foresight actually requires knowledge assessment in order to successfully advance to set long-term targets and visions. The example concerns the long-term sustainability strategy of the Netherlands. This section allows us to clarify the design of deliberation levels on a concrete case.

Four key Netherlands Ministries are committed to guide and support 4 long-term transitions to 2050 visions on sustainable development:

- Sustainable mobility (Transport Ministry)

- Sustainable use of biodiversity and natural resources (Foreign Affairs)

- Sustainable Agriculture (Agriculture Ministry)

- Sustainable Energy (Economic Affairs)

A major difference with previous policies is the adoption of a transition approach towards system innovations. System innovations aim at innovation at the level of systems such as Agriculture, Energy or Transport and focus on the conditions under which innovations can emerge and be managed at the system level, rather than on isolated particular technological findings. It aims at providing the right legal, social and economic conditions, under which important actors within the system can work together, learn from each other and mutually adopt new innovations consistent with intermediate and longer term goals. It may also include governmental assistance in funding technological forerunners in the field as currently is practiced for the Energy sector in the Netherlands.

Transition management acknowledges (based on Kemp 2004, Fourth National Environmental Programme (NMP4), 200I):

- Recognition of the international dimension and the need to develop long term visions.

- Short-term policies are informed and based on longer term policies or orientations.

- The government takes the role of a mediator: engage in steering, creating right conditions, engage in brokering services.

- To operate on open options, to stimulate knowledge/technology production and exchange

The determination to embark on an on long-term transition towards 2050 is in fact the outcome of a deliberation at the political level, determining that the normative boundary of deliberating further on more concrete policies should be "a shared concept of sustainability" rather than "predetermined future images that would fix choices for a long time"(Kemp, 2004). In order to achieve these long-term (2050) transitions: global scenarios and visions are developed on how these transitions should/would look like. In the case of energy, the 2050 long-term vision is to have an energy system almost entirely relying on renewable.At the same time concrete strategic scenarios and strategies are developed for the mid-long term (2020). Among others, these strategies result from backcasting (one method employed by Foresight exercises) from the 2050 long-term vision. In order to achieve transitions, transition arenas are identified in which all actors who are effected by or responsible for a particular transition are identified and bound into a process of making concrete steps towards the direction required and made compatible with a long term process. Transition paths with the help of, among others, experiments, are developed in order to make the road toward 2020 strategic goals achievable (in the case of the Energy sector, around 70 transition experiments have been proposed). The transition paths are multiple in nature in order to avoid a foreclosure of options (see for an overview of the interrelationships between long-term visions and mid term strategies, in figure I, which informs the Dutch Ministry of Economic Affairs approach, www.minez.nl, a well worked out plan for transitions to biomass use has also been published (Biomass, the green tool for transition, 2004). 


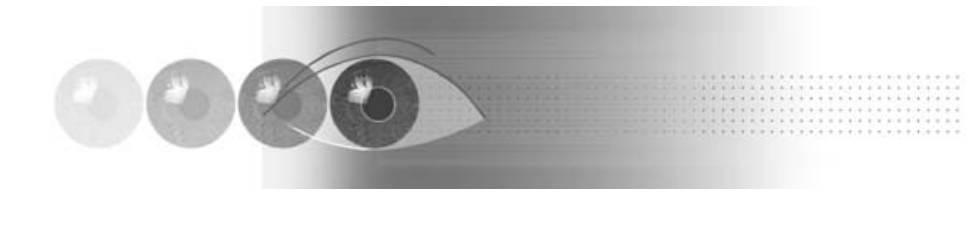

Much depends on feedback between current assessments, mid term strategies and long-term visions and scenarios. Strategies, assessments and long-term scenarios are developed by participating parties including academic researchers. Here a series of deliberation levels are introduced. Deliberation on the transition paths have led to the adoption of the normative criteria of cheap, reliable and low-carbon for energy (Kemp 2004), and thus represent normative considerations at the science/policy interface in terminology we have used above. Deliberation at the policy level on the basis of these criteria will have to take into account, among others, the constraint that the employment of biomass should not affect negative impacts for developing countries. Deliberation with stakeholders (e.g. deliberations at the science/policy/society interface) has led to the adoption of normative flexible ambitions (rather than fixed targets, and in fact represent an example of transformable standard we explained above) that biomass should account for 10 - I5 percent in energy power production and 15-20 percent in transport. The involvement of stakeholders has also led to the perhaps unusual coalition of green groups and business operators adopting in 2003 a manifest with a plea for the use of a trans-European emission trading system for greenhouse emissions with long-term ceilings.

Foresight is thus embedded, as one of many means of expertise/and participatory input to this process of transition management. 2004 was the starting year. This example of an advanced embedded foresight shows that there was a successful "design" of deliberation levels, interrelating to each other and bound by constraints to select on quality.

Figure I:The relation between long-term visions, strategic goals and in-between assessments

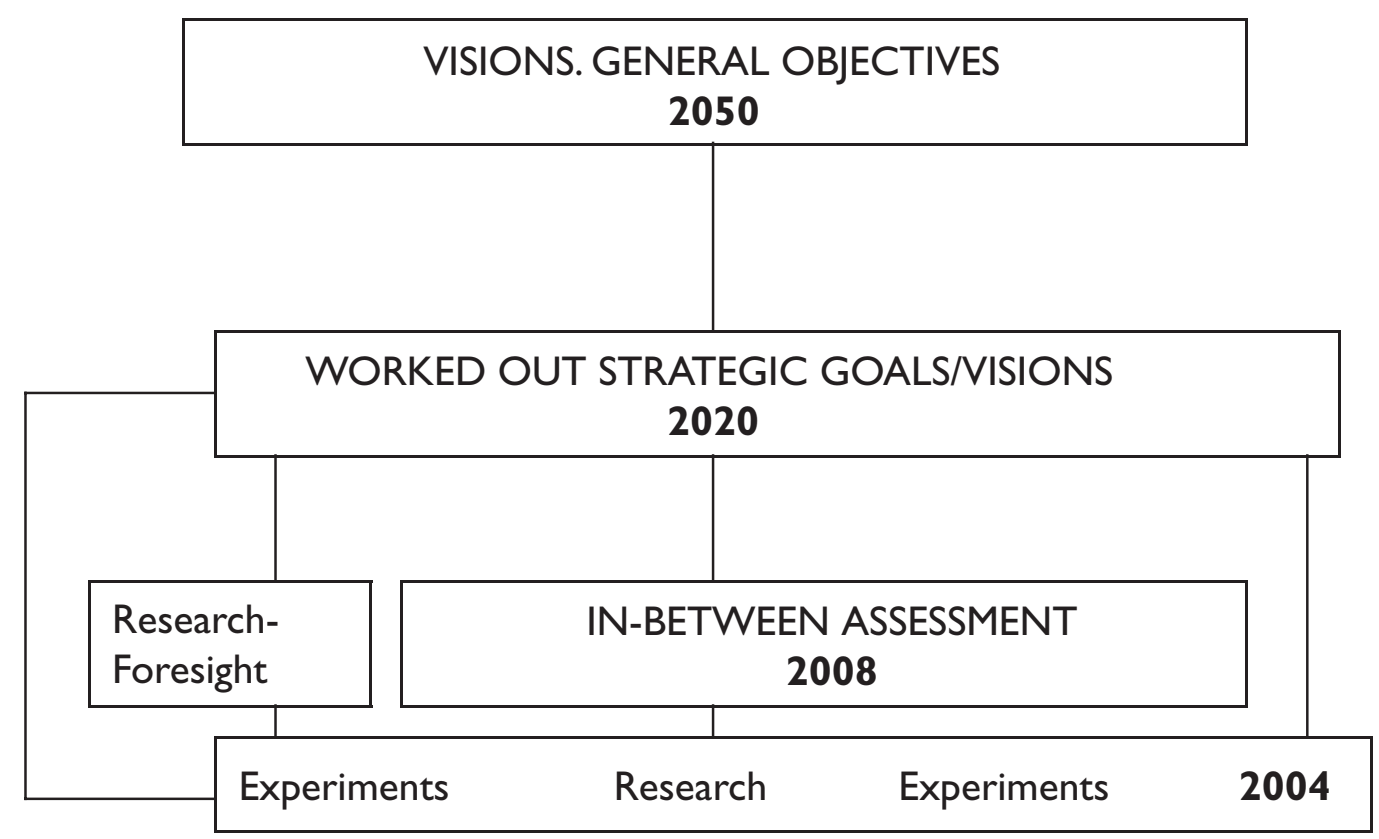

\section{Foresight as interfaces between science, society and policy}

The challenges that science related to public policy face today, have to do with the increasing recognition of complexity of socio-environmental problems, requiring (ideally) extended engagement of relevant societal sectors for their framing, assessment, monitoring, and an extended deliberation processes.

Foresight aims at providing visions of the future to explore effective strategic policy. Envisioning is inherent to any technological, environmental and social activity. It becomes explicitly or implicitly in assessment methodologies, policy documents or political discourse. Foresight is naturally bound by uncertainty and ignorance, value laden and requires different types of knowledge as the background and the justification of the exercises' outcomes. 


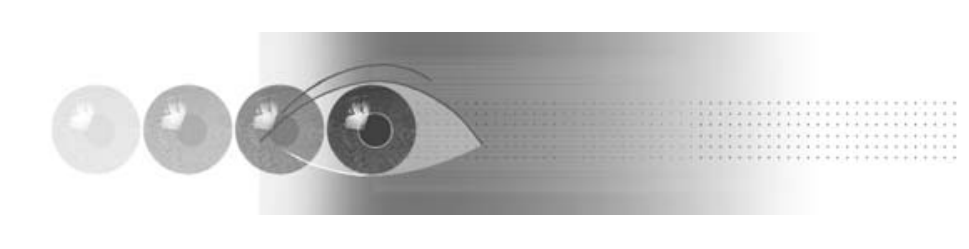

Foresight can be viewed as an interface between science and policy and concerned spheres of the society, implying flows of knowledge among these spheres - see figure 2. As pointed out in earlier sections, there is a need to put a strong effort on the quality assessment of those knowledge flows, ideally by engaging an "extended peer community".

Figure 2: Foresight process, interfaces implying flows of knowledge and quality assessment requirements

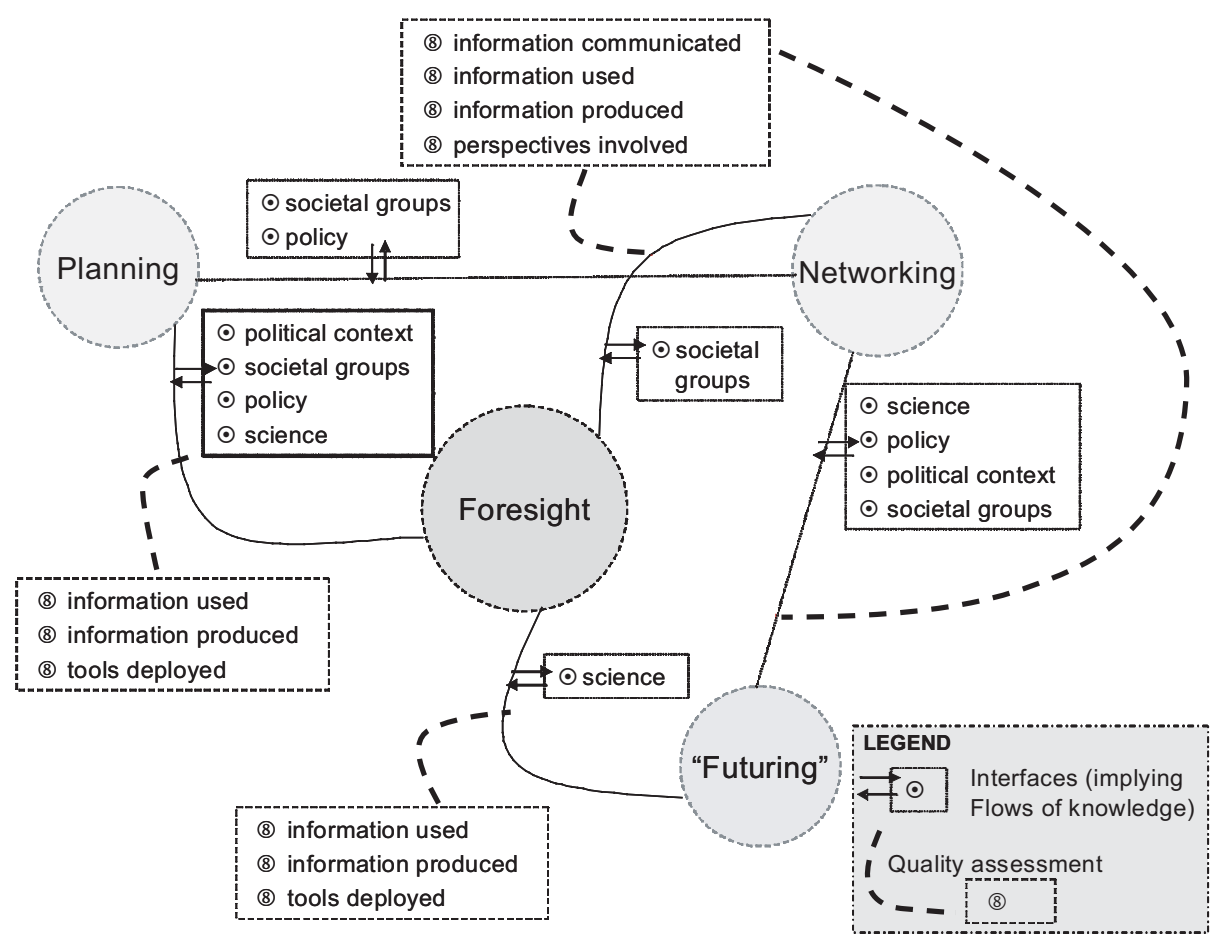

Foresight exercises are (in) themselves "engagers" of wider sectors of the civil society in the assessment of the relevant knowledge and the governance of its production. Hence, an important element of such type of activity should include a process of assessment of the "knowledges" that support resulting policies. This is what this section proposes and discusses.

\section{I. Foresight and knowledge flows}

In foresight, planning, networking and "futuring" are the base activities that feed such a type of exercise (Miles, 2003). Those activities (see box I for what they entail), involve different types of knowledge flows within each activity and across activities, therefore different types of information, audiences and processes are expected. For instance, "futuring" entails issue framing, identification of indicators, mechanisms for evaluation, etc. that are laden by issues of scales, perspectives and values, involved "audiences", etc. Foresight is understood as a collective exercise, and therefore networking is a fundamental activity for sharing visions, exchange of knowledge, creating shared ground and desirably social learning. That clearly, implies the creation of spaces of shared understanding and hence, entails communication and creation of appropriate spaces for sharing knowledge and possibly to co-create new one.

Finally, planning is the other activity that both informs a foresight exercise and gathers insights from it about strategies and planned actions.

The quality of these information flows will influence the outcomes of a foresight exercise since these activities involve a number of information flows that are generated by different sources and address different audiences. It is also important to recall here, that foresight leads to different types of outputs, but basically 


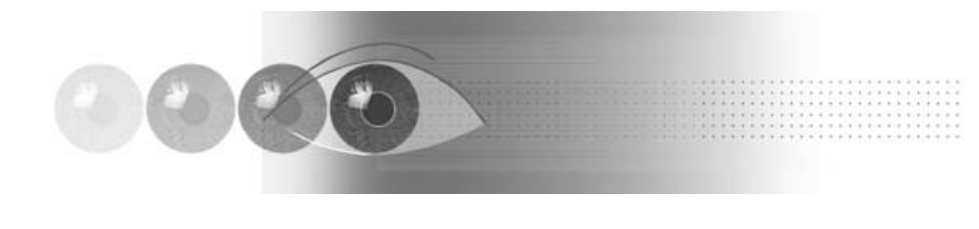

it is an exercise that allows design and tuning of policies for a long-term future, since it allows promoting a space of dialogue on options for the future, desirable and undesirable futures and ways to achieve them. Quality assurance of the inputs and outcomes of this exercise become a condition sine qua non to ensure trust among those who participate and those who use the outcomes. In the remaining of this document, a structure to assess knowledge flows in this type of exercise is proposed, addressing possible divides arising in foresight related activities that eventually inform policy making.

Box 3: Foresight base activities (after Keenan, Miles, 2003)

- "Futuring": deploys futures methods, forecasting techniques, modelling and visionary approaches, etc.

- Planning: deploys planning tools and techniques, OR and systems approaches, etc.

- Networking: deploys networking tools and techniques, group work and facilitation, survey approaches, etc.

\subsection{Knowledge divide}

Knowledge is an asset to initiate issue framing, exploring uncertainty, possibilities and action; already within scientific practice, disciplinary integrations suffer from inherent differences of framing, methods, scales, etc. and therefore it is not surprising that attempts to represent knowledge as a co-produced outcome using scientific and societal inputs will have to depart from probably efforts of conviviality (using the expression of Ivan Illich (1973)) and of creating shared understanding and language. In foresight, networking implies precisely the creation of spaces where different types of knowledge eventually will constitute what Gibbons (1999) called socially robust knowledge.

We argue that potential knowledge divides arise due to these two types of issues, on one hand the quality of knowledge and on the other hand the conviviality of knowledge. Whereas the former, relates to aspects of availability, accessibility, relevance, fitness for purpose and legitimacy, i.e. the pedigree ${ }^{7}$ of information used, the latter relates to the diversity of interpretations inherent to diverse value systems and existing platforms for understanding, sharing, learning and communicating. Hence, we are here concerned with two types of divide, a knowledge production divide, and a knowledge usage divide, which comprise broad communication aspects (including, for instance, lack of it within scientific contexts that lead to scientific disciplinary fragmentation and indifference).

\subsection{Production of Knowledge - Divide}

The quality check of scientific information is governed by long standing practice and rules. Hence, excellence of scientific outcomes should be scrutinised by using peer review rules. Foresight is concerned with societal issues and policies, where scientific knowledge is relevant but cannot alone provide insights and answers. These activities involve a number of information flows that are generated by different sources and address different audiences. Although internal quality of the knowledge deployed in governance processes is surely important, the context of its production and usage should also be taken into account within quality checks that should both apply for knowledge production and knowledge use. We will describe, by using the aforementioned categories, how and where possible divides may arise across society, from knowledge production and deployment in foresight activities.

\footnotetext{
${ }_{7}^{7}$ These are categories of the information Pedigree scheme included in NUSAP - Numeral Unit Spread Assessment Pedigree (Funtowicz \& Ravetz, 1990)
} and further developed in (Corral, 2000) for assessment of information in decision processes - Pedigree Exploration Tool (PET). 


\section{Availability and Accessibility}

These are two distinct aspects of information divide.Availability of information can undermine a whole debate, also relevant in processes with regional disparities. It relates directly to relevant knowledge uncertainties and it obviously affects the ways decision and policies are developed.

Despite the explosion of places (virtual and non-virtual) where information can be gathered, accessibility to information remains one of the main reasons for a poor information basis. Accessibility is here understood as a broad issue, not only restricted to access to scientific or technical information but also including access to holders or sources of knowledge other than scientific.An unequal access to information and knowledge results in an unbalanced capacity to use information and knowledge to develop.Accessibility has also another dimension, which does not relate to "infrastructure", but to "legibility" of the information by the community of concern, which will be explored in a subsequent section.

\section{Relevance}

Recently O'Malley et al. (2003) pointed out that the quality of environmental information with which one claims to influence policy discussions, must "go beyond the basic notions of scientific excellence". "For information to be used and useful, and not itself be the subject of debate, it should meet three standards: it should be policy relevant, technically credible and politically legitimate". In the political and policy making discourse, a primary criterion for the quality of information is relevance, irrespective of the domain. Hence information irrelevance could make a policy process vulnerable or a sham foresight exercise.

\section{Fitness for purpose}

Fitness for purpose, one of the key categories to assess quality of a product or process, concerns issues such as accuracy, completeness and adequacy of knowledge both within the context in which is going to be used and for the relevant policy or governance issue. Again, here determining what knowledge fits the purpose should be a shared decision, making the whole notion of rigour tighter, since such decision corresponds to a broader set of requirements.

\section{Legitimacy}

The choice of the knowledge base that should be considered is of great importance here. Two aspects are relevant. The first aspect concerns the possible strategic use of knowledge by politicians. S. Jasanoff in Liberatore \& Funtowicz (2003) alerts for the danger that politicians could be using expertise that serves specific political agendas rather than that they will search for knowledge that may lead to robust but, possibly unacceptable findings in terms of their political agenda.

The second aspect relates to legitimacy concerns of the sources of used information. The credibility and legitimacy of knowledge rely directly on the trust we can have in participatory policy making. The success of such participatory policy making is dependent on extended dialogues or the implementation of shared spaces of learning and building of robust policies. Credibility problems may change the focus of the debates and dialogues.

\subsubsection{Usage of Knowledge - Divide}

Divides occurring from knowledge sharing, are probably at the basis of major societal divides. Knowledge sharing includes its communication and sharing among plural perspectives and values which arise from by different walks of life, disciplinary backgrounds, etc. of those involved.A major issue concerns the inexistence of established ways to create "knowledge sharing platforms", that is established or formal ways in the form of social/societal opportunities to organise, mediate, exchange, co-produce and communicate different types of knowledge. There is already a great deal of experiences that explored ways of building such platforms 
for inclusive participatory exploration of policy and foresight in particular: creation of spaces where issues such as communication of knowledge among different perspectives in the sense of format, settings, knowledge accessibility in terms of legibility, language and jargons, congruency with context are essential dimensions of knowledge quality for policy and foresight in particular.

The issue of context determines the forms of relationship and contract between institutions and the society and therefore the forms of involvement of the latter in decisions processes (see also the sections where we discuss deliberation levels). If participation is seen as essentially a process through which also knowledge is being produced, the common understanding of the actors' multiple languages is essential to achieve effective dialogues and outcomes. Burgess et al. (2000) pointed out that the bringing together of different knowledge, experiences and actions into a management scheme depends on the abilities of the different actors to accommodate and make sense of each others' worlds. The processes we talk about here are processes that aim at providing shared ground, by which points of view are presented against an information background made up of different relevant knowledge contributions. For instance, where science is relevant, there might be a need to work on scientific jargon, and depending on the audience, specific interfaces between the scientific issues and non-specialists might have to be built in. Fischer (2000) makes an interesting remark about the "distance" that has been deepened in latter years between experts and mass citizenry. Instead of facilitating democracy, professional experts have given shape to a more technocratic form of decision making, with elitist rather than democratic features.

Hence, the divide arising from poor exchange and communication is likely to jeopardise the robustness of any type of policy exercise including foresight. This issue is specially addressed in the quality assessment checklist proposed in the remaining section of this paper.

\section{Knowledge Assessment \& Pedigree structure to assess quality of "foresight knowledge"}

\section{I Knowledge Assessment Methodologies}

"Knowledge assessment methodologies" (KAM) is a label that we found useful to implement the concepts of extended quality assurance and extended peer review. It consists of a group of methods that assess knowledge by establishing platforms for sharing different knowledge inputs, and different types of quality check.

This framework responds to the increasing needs for better interfaces between science and governance and the needs for citizens regarding access and participation in decision-making processes. KAM refers to tools for the quality assurance of knowledge inputs to extended decision-making processes. Technologies include formal methods of analysis to assess the quality of policy-relevant information, products and of decisionmaking processes. These are complemented by more informal methods such as non-algorithmic multi-criteria and participatory processes facilitated by ICT.

A major activity within KAM is building of dialogues between the vernacular knowledge and systems science and the creation of shared ground and understandings between "formal" and "informal" knowledge. These methodologies result also from research that explores the contexts in which such gathering can be operational and aim at creating the contexts of exchange between science and wider sectors of the society, i.e. partnerships for knowledge sharing in contexts of personal or community decisions or European policy settings. These bridge perspectives for collective benefits.

\subsection{The Pedigree Structure}

In figure I we illustrate where quality assurance of knowledge deployed in foresight exercises is an important step, given the types of interfaces that can emerge in the foresight process. The flows concern essentially with issues such as framing (multiple perspectives involved), the knowledge used for the 
background of the process, the tools deployed, the knowledge produced and the knowledge communicated across the interfaces.

Hereafter we propose a preliminary structure of check items for the activities carried out in foresight. These items are based on the pedigree categories developed in Corral Quintana (2000) and adapted for the specific context of foresight. This intends to be a sort of check list for quality assurance of knowledge flows in the foresight process.

\subsection{Information Pedigree for "Futuring" and Planning}

This includes for instance "Fitness for purpose" which is a bridge between the analysis of the applicability of the information and its related uncertainty (see appendix for quality categories).

\subsubsection{Quality of tools deployed in "Futuring" and Planning}

This is about the toolbox deployed in the process. It covers fitness for purpose, degrees of transformation of information resulting from the application of the toolbox, etc ( see Appendix for associated quality categories).

\subsubsection{Information communicated through Networking}

This section is dedicated to the assessment of the quality of the outcomes of the activities of "futuring" or planning in networking activities in terms of communication of information (see Appendix for associated quality categories).

\subsubsection{Information communicated from networking into the foresight exercise}

\section{Acknowledgement of Input}

Introduction of information coming from Networking into Futuring or Planning exercises.

Assuming that there is a specific activity through which relevant information, perspectives and values are unveiled from the Networking activities, the question is whether this input is specifically acknowledged in several phases of foresight process and reflected in the eventual visions (see Appendix for associated quality categories).

a.The levels or steps at which knowledge assessment is applied;

b. The people involved in the assessment process;

c. The quality categories relevant to analyse the knowledge produced or exchanged. 


\section{REFERENCES}

CEC. (1992). Council directive 92/43/EEC of 2 I May on the Conservation of Natural Habitats and of Wild Fauna and Flora. Official Journal L206, 22/07/I992. Pp. 007-0050.

CEC. (200I). A Sustainable Europe for a Better World:A European Union Strategy for Sustainable Development. $\operatorname{COM}(2001) 264$ final.

Cohen, J. (2004). 'Procedure and Substance in Deliberative Democracy' in S. Benhabib (ed) Democracy and Difference: Contesting the Boundaries of the Political, Princeton, New Jersey: Princeton University Press.

Corral Quintana, Serafín (2000). “Una Metodología Integrada de Exploración de los Procesos de Elaboración de Políticas Públicas”. Universidad de La Laguna,Tenerife. EC - JRC: EUR 19724 ES.

De Marchi B., Funtowicz, S., Guimarães Pereira, A. (200I). From the Right to Be Informed to the Right to Participate: Responding to the Evolution of the European Legislation with ICT. International Journal of Environment and Pollution, I5(I), I-2I.

Dryzek,J.S. (1990). Discursive democracy: politics, policy, and political science, Cambridge: Cambridge University Press.

Dutch Ministry for Economic Affairs, http://www.minez.nl

Dutch Ministry for Economic Affairs (2004), Biomass: the green tool for transition.

European Foundation for the Improvement of Living and Working Conditions (2003), Handbook of Knowledge Society Foresight, Dublin.

Flyvbjerg, B. (2003). Megaprojects and Risk: An Anatomy of Ambition. Book with Nils Bruzelius and Werner Rothengatter. Cambridge University Press.

Fischer, F. (2003). Reframing Public Policy. Discursive Politics and Deliberative Practices. Oxford: Oxford University Press.

Funtowicz, S. O. and Ravetz,J.R. (1990). Uncertainty and Quality in Science for Policy. Dordrecht: Kluwer Academic Press.

Gibbons, M. (1999)."Science's new social contract with society" Nature 402: C8I-C84.

Grin, J., Felix, F., Bos B. and Spoelstra S. (2004). Practices for reflexive design: lessons from a Dutch programme on sustainable agriculture, Int. J. Foresight and Innovation Policy.Vol I. Nos I/2 , pp. I26-I49.

Grove-White, R., Kearnes, R., McNaghten, P.,Wynne, B and Miller, P. (2004). From bio-nano: learning the lessons, interrogating the comparison, Paper presented at the $4 \mathrm{~S}$ and EASST conference "Public Proofs. Science, Technology and Democracy, August 25-28 2004, Paris: Ecole des Mines.

Grunwald,A. (2004). Strategic knowledge for sustainable development: the need for reflexivity and learning at the interface between science and society in: Int.J. Foresight and Innovation Policy, Vol I, Nos I/2.

Guimarães Pereira, Â. \& Corral Quintana, S. (200I). Communicating and reporting uncertainty in environmental assessment.Available in http://www.nusap.net. 
Hoppe, R. (2002). Rethinking the puzzles of Science-policy nexus: Boundary traffic, boundary work and the mutual transgression between STS and Policy Studies, Paper presented at the EASST 2002 conference, Responsibility under Uncertainty, York, 3 I July-3 August 2002.

Keenan, M, I Miles, Jari Koi-Ova (2003). Handbook of Knowledge Society Foresight

European Foundation, Dublin, available at: http://www.eurofound.eu.int/transversal/foresight.htm

Kemp, R. (2004). Dutch policies to manage the Transition to Sustainable Energy, Paper presented at the $4 S$ and EASST conference "Public Proofs. Science, Technology and Democracy,August 25-28 2004, Paris: Ecole des Mines.

Illich, I. (1973). Tools for Conviviality. New York: Harper \& Son.

Liberatore,A. \& Funtowicz, S. (2003). Democratising expertise, expertising democracy: what does this mean, and why bother? In Liberatore, A. and S. Funtowicz (guest eds) Science and Public Policy special issue. 30(3): | $46-150$.

Loveridge, D. (2004). Foresight. Programme of Policy Research in Engineering Science and Technology, University of Manchester: p.9.

National Environmental Programme (NMP 4) (200I), Een wereld en een wil, werken aan duurzaamheid (A World and a willing), VROM, Den Haag.

Neblo, M.A. (2004). Thinking through Democracy: Deliberative Politics in Theory \& Practice, Paper presented at the Conference on "Empirical Approaches to Deliberative Politics" European University Institute, Firenze, 2I-22 May 2004.

O’Malley, R., Cavender-Bares, K. \& Clarck, W. C. (2003). “Better” Data, Not as Simple as It Might Seen. Environment 45 (4). Pp. 9-18.

Rand Europe, Improving the science/policy relationship with the help of foresight: a European Perspective, service contract-study for the European Commission, forthcoming December 2005.

Schomberg, R. von (ed) (2003). Science, Politics and Morality. Scientific Uncertainty and Decision Making. Dordrecht: Kluwer Academic Publishers.

Sluijs, J.P van der, et al (2003). RIVM/MNP Guidance for Uncertainty Assessment and Communication. Utrecht/Bilthoven: Copernicus Institute and RIVM.

Veld, R. J. In't (ed). (200I). The rehabilitation of Cassandra. A methodological discourse on future research for environmental and spatial policy. Utrecht: Lemma Bv. 


\section{ANNEX}

\section{Information Pedigree for "Futuring" and Planning}

\section{Fitness for purpose}

This category is a bridge between the analysis of the applicability of the information and its related uncertainty.Adequacy reflects whether the available information has been developed specifically for the problem at hand or rather it was developed for other cases. An analysis of the degree of connectivity between the information available and the relevant issue is necessary. This is done through categories ranging from complete fitness (taking place when the information is developed specifically for the specific problem) to weak fitness (when the information used has been generated in other circumstances where similar problems have been addressed). Scales of low adequacy apply, when the applied data come from studies about other different issues (Corral Quintana, 2000).

(a) Correspondence between information used and issues addressed - Adequacy, Relevance

Adequacy of information - categories:

- Specific (complete fitness)

- Applied in Similar Cases

- Generic to the issue

- Generic to all sorts of problems (weak fitness)

- Other (state)

By adequacy, it is meant the specificity of correspondence between the issue addressed and the information used.

Relevance of information in relation to the objectives of the activity- categories:

- Relevant

- Fairly relevant

- Irrelevant

(b) Accuracy of information - are uncertainties clearly stated? - categories:
Relevance. Evaluates the relevance of this information in relation to the case study (how the available information corresponds to the relevant issues)
- Highly accurate

- Accurate - Uncertainties recognised

- Accuracy difficult to judge; Uncertainties not stated

- Not accurate

- Unknown
Accuracy. Given by the transparency in which uncertainty and lacks of information are given. 
(c) Comprehensiveness/completeness of information. Has the information available to accomplish the tasks involved in "futuring" and planning fulfilled the information needs? Or: Has the information used (from the available) fulfilled the information needs? - categories:

- Total fulfilment

- Comprehensive and fulfilling

- Partially comprehensive

- Not comprehensive

- Unknown

\section{Completeness: Level of} incompleteness of data series or aspects of the process in which data or knowledge are not controlled (or controllable), or are even incomplete.

\section{Applicability}

(a) Access \& Availability:Was the information available? Was the information accessible (even if available)?

Access of information - categories:

- Total Availability

- Available only at the Academic or other expert Spheres

- Not public: need for permits \& credentials

- Confidential - no access

- Unknown

(b) Intelligibility Is information intelligible for those carrying out the work of the project (or who can understand the information collected or yet which audiences was the information targeted to?). Intelligibility of the information - categories:

- To All

- Relevant Actors

- Political Sphere

- Expert Consultancy

- Academic Sphere

\section{Accessibility. Conditions of} accessibility to relevant information. If the information is not openly available (or available to a restricted audience) the entire process will be affected. This category is divided into five types ranging from the highest availability and accessibility to the lowest where the information is unavailable.
Intelligibility: defined as the level of training needed by the agents to be able to interpret (and manipulate, perhaps!) relevant information. It ranges from a total understanding of the information by all agents implicated in the process (actors involved) to a situation where only the experts in the relevant field can consider/understand it. Between those two extremes, three more situations are contemplated:Those consist of the politico-institutional, the consultancy and the academic contexts. 


\section{Reliability}

The evaluation of the Reliability of the information ranges from its internal aspects (such as its generation and verification) to those more external, such as those related to the acceptance of the specific information by the relevant community.

(a) Control (Sources, verification, colleague consensus)

Sources of information - Where? (information providers). What sources have been used? - Source as place where information was available. Categories:

\begin{tabular}{|c|c|}
\hline Scientific Literature & $\begin{array}{l}\text { Peer reviewed journals } \\
\text { Newspapers or magazines }\end{array}$ \\
\hline Research Project reports & \\
\hline Institutional Publications & $\begin{array}{l}\text { Governmental } \\
\text { International institutions } \\
\text { Non-governmental organisations }\end{array}$ \\
\hline INTERNET sites & $\begin{array}{l}\text { Institutional } \\
\text { Non-governmental } \\
\text { Commercial } \\
\text { Educational } \\
\text { Personal }\end{array}$ \\
\hline Expert/scientific consultancy & \\
\hline Social research & $\begin{array}{l}\text { Interviews with stakeholders } \\
\text { Group meetings }\end{array}$ \\
\hline
\end{tabular}


Sources of information - Sources of generation of information categories:
Method of Generation:'origins' of the information that will be used during the process. Ranges from the experimental sort (experimentation) with a small and controlled degree of uncertainty to the estimations made by experts.

- Experts

- Public Sphere

- Consultancy

- Stakeholder Opinions

- Perceptions of population

\section{Verification categories:}

- External

- Independent

- Regular

- Occasional

- None / Unknown

Colleague consensus categories:

- Complete

- Some Discrepancies

- Competing Schools

- Not Enough Knowledge

- Unknown
Sources of generation information. Specifies the type of information being analysed, ranging from experts' knowledge (scientific knowledge), Public Institutions' position, information generated by stakeholders (consultancy), opinions of the different agents involved in the issue and the perceptions of the population at large about the relevant issue (perceptions of the population).
Verification. The source of the information is considered here as relevant as the knowledge of whether the data have been checked. It ranges from an external control considered as assuring a greater reliability, to situations in which such control does not exist or it is unknown (none).
Colleague consensus. It reflects the degree of acceptance of the analysed information by the rest of researchers working in the same field. 
(b) Confidence (Extended peer acceptance, legitimacy)

Extended peer acceptance categories:

\begin{tabular}{l} 
- Total \\
- High \\
- Medium \\
- Low \\
- None \\
\hline
\end{tabular}

Extended peer acceptance. Whereas the previous category reflects the degree of acceptance of the information by the expert's community, here it is considered the level of acceptance by the rest of actors involved in the process.

Sources of Legitimacy - categories:

- Academic Sphere

- Perception

(Traditional Heritage)

- Mass-media

- Religion

- Public Sphere
Legitimacy. specifies the legitimising framework of the information. In many cases the credibility of the data is closely related to the Institution that generates or sanctions it. Several distinctions are used, from the academic or political context to perceptions shaped by traditions and cultural heritage of the community involved (generally speaking, local knowledge).

\section{Quality of tools deployed in "Futuring" and Planning}

\section{Fitness for purpose}

Adequacy/ Applicability - Are the tools deployed in the activities adequate to the problematique? Were the models used fully applicable to the work done in "futuring" or planning?

\section{- Specific}

- Applied in Similar Cases

- Generic to the issue

- Generic to all sorts of problems

- Other (state)
By adequacy, it is meant the specificity of correspondence between the issue addressed and the information used. 
Relevance of tools (models, etc.) in regards to the objectives of the present project - categories:

- Relevant

- Fairly relevant

- Irrelevant
Evaluates the relevance of the tools used in relation to the foresight exercise (e.g. models used)

Adaptability/Flexibility - Could the tools (models, etc.) be adapted/ tuned to the questions to be addressed?

- Flexible

- Fairly flexible

- Inflexible

Transformation/ encoding - What kinds of information 'transformations' are performed through the tools and methods?

- None

- Simplifications by highlighting 'key' aspects (state)

- Aggregations

- Extrapolations

- Total encryption
The question here is whether the tools used in the foresight exercise can be adapted to the particular issue.
The issue is whether the tools used imply a great deal of transformations that decrease the accuracy of outcomes.

\section{Transparency}

Models documentation - Are the tools, models and methods deployed documented?

- Fully

- Partially - not comprehensive

- Not at all
Documentation is an essential aspect of transparency. It is related to justification of choices. 
Sources of information - Are the sources of information used in the models clearly stated?

- Fully

- Partially - not comprehensive

- Not at all
The sources of information stated are an aspect of the legitimacy of the information.

Apart from the sources stated are there references to other work that could be relevant to the overall application?

Arbitrariness - scientific set-up:Are assumptions clearly stated while applying the models, methods and tools through the activities?

- Assumptions fully documented

- Assumptions partially documented

- Not at all

\section{Legitimacy}

Collegial consensus categories for methodologies used:

- Complete

- Some Discrepancies

- Competing Schools

- Not Enough Knowledge

- Unknown
Arbitrariness: this is an important moment of the quality assessment since, it evaluates if choices are adequately justified.
Colleague consensus. It reflects the degree of acceptance of the analysed information by the rest of researchers working in the same field. 


\section{Information communicated through Networking}

\section{Intelligibility}

Compliance with target audience Adapted to the timings of the audience - is there an overview/ summary provided? Adapted to the skills of the audience (format)?

- Balanced outcomes with illustrations where appropriate and summaries of main points

- Academic experts sphere only

- Cryptic writing - Only for selected users

- Impossible to pass from the first screen

Compliance: Formats, timings adequacy to the audience or network members.

Accessibility of outcomes to the audience

- Public - available in the INTERNET or a public body

Accessibility. Access easiness to outcomes.

- Public - available upon request

- Restricted access

- Not accessible

\section{Transparency}

- Sources of the information stated (reliability, etc.)

- Methods used stated

- No information on sources \& methods is provided

Transparency. Documentation available to the network members should be fully documented for transparency sake.

Is citation of other similar exercises done?

\begin{tabular}{|l|l|}
\hline YES & NO \\
\hline
\end{tabular}




\section{Communication of Uncertainties ${ }^{10}$}

Recognition:Are major uncertainties taken into account?

- In the problem formulation/framing

-Within the methodology

- Communicated informally to the audience

- No account for uncertainties

Statement: How were uncertainties stated?

- Mathematical formulation (statistics with associated probabilities, sensitivity analysis, etc.)

- Narrative through the statement of assumptions made or verbal statements

- Judgements on information sources

- Statement of ignorance

- None
Recognition: the first step is acknowledgement of uncertainties; foresight exercises are inherently bound by those.
Statement. What sort of method is used to state uncertainties. Great elaboration can actually imply more uncertainty.

Are implications for policy and for social context been stated?

\begin{tabular}{|l|l|}
\hline YES & NO \\
\hline
\end{tabular}

Are uncertainty relations with risk (namely consequences for different risk management strategies) stated?

\begin{tabular}{|l|l|}
\hline YES & NO \\
\hline
\end{tabular}

\section{Pedigree statement}

Does it offer pedigree of results?

- References

- Background documents

- Figures' pedigree

- Others
Statement. Documentation and statement of origin of sources is another aspect of legitimacy, transparency and trust. 
4. Information communicated from networking into the foresight exercise

Acknowledgement of Input

- Framing

- Scoping

- Assessment

- Foresight outcomes:Visions, Planning strategies, etc. 
European Commission

EUR 21957 - Deliberating Foresight Knowledge for Policy and Foresight Knowledge Assessment Luxembourg: Office for Official Publications of the European Communities

$2005-36$ pp. $-21,0 \times 29,7 \mathrm{~cm}$

ISBN 92-79-00678-9

\section{SALES AND SUBSCRIPTIONS}

Publications for sale produced by the Office for Official Publications of the European Communities are available from our sales agents throughout the world.

You can find the list of sales agents on the Publications Office website (http://publications.eu.int) or you can apply for it by fax (352) 29 29-42758.

Contact the sales agent of your choice and place your order. 
